------ Raf. J. Sci., Vol. 25, No.2 pp. 95-100, 2014------

\title{
Comparative Study for Temperature Dependence of Bulk Modulus for Solids: Pyrope Garnet as an Example
}

\author{
Khaled S. Hameed \\ Al-Mutamayzeen Secondary School \\ Directorate of Education in Nineveh Governorate \\ Nineveh, Iraq
}

(Received $12 / 5 / 2013$; Accepted 16/7/2013)

\begin{abstract}
A comparative study for temperature dependence of bulk modulus and an investigation for the evolution of this variation have been established, by using five different theoretical equations, according to their historical development. The theoretical results obtained in this work have been compared with experimental data. Pyrope garnet, $\mathrm{Mg} 3 \mathrm{Al} 2(\mathrm{SiO} 4) 3$, has been chosen as an example for solid materials.
\end{abstract}

Keywords: bulk modulus, high temperature, pyrope garnet.

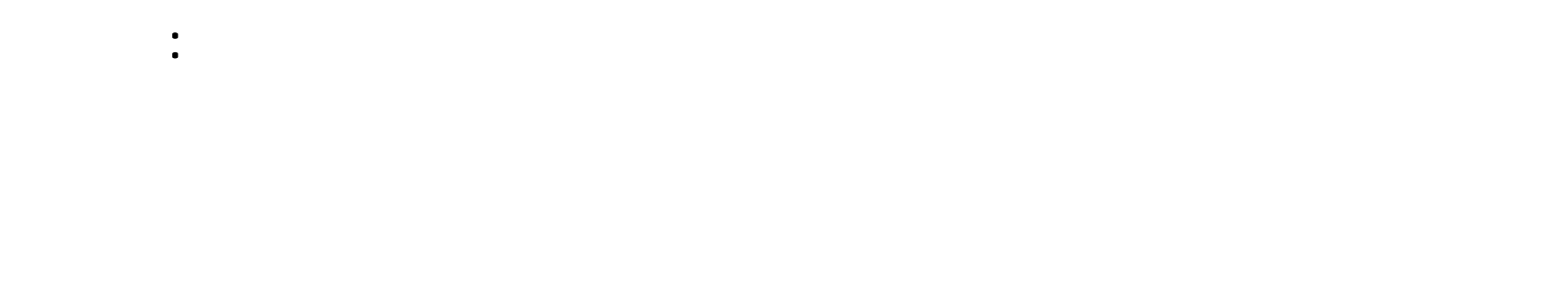

يقهم هذا البحث درلسةُ مقارنةّ لتغير معلمل المرونة الحجمي مع ارتفاع درج ـة الح ـرارة، ولستق صاء ظور هسلب هذا التغير من خلال لستخدلم خهس معادلات ظارية مختلفة وفقاً لظورها التاريخي. فضلاً عن مقارنة النتائيج الظية المستحصلة مع بيانت تججريبية. مم لختيار العق ق الأحم ـر، Mg3A12(SiO4)3، مثالًا للمواد الصلبة.

الكامل الدالة:معلمل المرونة الحجم، درجة الحرارة العالية، العقق الأحمر.

\section{INTRODUCTION}

The behavior of minerals under the influence of high temperature, has attracted the attention of theoretical as well as experimental workers (Isaak et al.,1989; Anderson et al., 1992; Kumar, 1996). The knowledge of elasticity of the minerals is useful for interpreting the structure and composition of the lower mantle and also in seismic studies (Upadhyay et $a l ., 2011)$. Considerable efforts have been made to predict the equation of state of minerals under varying conditions of pressure using diamond- anvil cell. However, fewer efforts have been made under the effect of temperature at room pressure. 
Garnet is one of the most abundant mineral constituents in the earth's upper mantle to mantle transition region. Elastic properties of pyrope have been the focus of extensive experimental and computational studies. Most of the high pressure experimental studies for pyrope were carried out at ambient temperature (Sinogeikin and Bass, 2000; Chen et al., 1999; Zhang and Herzberg, 1994) or high temperature-room pressure (Sinogeikin and Bass, 2002). In recent years, $A b$ initio molecular dynamics which simulates stress-strain relationships at elevated pressure and temperature conditions, has been used to quantify thermo-elasticity of pyrope (Li et al., 2011). Pyrope is the only member of the garnet family which always displays red coloration in natural samples, and because of this characteristic it got its name. The composition of pure pyrope is $\mathrm{Mg}_{3} \mathrm{Al}_{2}\left(\mathrm{SiO}_{4}\right)_{3}$. It is considered to be the major end-member garnet in the earth's upper mantle and transition zone. So we chose pyrope as an example to study the validity of several theoretical methods for calculating the temperature dependence of bulk modulus by comparing them with the experimental data.

\section{THEORETICAL DETAILS}

The bulk modulus is a material's resistance to uniform compression, given by the 2ndorder volume derivative of the material's free energy; sometimes referred to as "incompressibility" (Murphy, 2012). Many isothermal equations of state EOS require knowing the value of the bulk modulus at the temperature of interest. The relationship between the pressure and the volume is given by the isothermal bulk modulus $\left(B_{T}\right)$ :

$$
B_{T}=-V\left(\frac{\partial P}{\partial V}\right)
$$

The experiments show that both the volume coefficient of expansion and the isothermal bulk modulus are pressure and temperature dependent.

The bulk modulus varies with temperature, this variation is studied theoretically using several methods. We calculate the results of these methods as follow:

\section{Method 1}

The following equation is presented by Kumar (Kumar, 1996 ; Pal et al., 1998)

$$
B_{T}=B_{o}\left[1-\alpha_{o} \delta_{T}\left(T-T_{o}\right)\right]
$$

Where: $B_{T}$ is bulk modulus at temperature $T . B_{o}$ is bulk modulus at room temperature $\left(T_{o}\right) . \alpha_{\mathrm{o}}$ is the coefficient of thermal volume expansion at ambient conditions. $\delta_{T}$ is the Anderson-Gruneisen parameter which is considered to be temperature independent in this method.

\section{Method 2}

The mathematical form of Kumar EOS reads as (Kumar and Bedi, 1996):

$$
\frac{V}{V_{o}}=1-\frac{1}{A} \ln \left[1+\frac{A}{B_{o}}\left\{P-\alpha_{o} B_{o}\left(T-T_{o}\right)\right\}\right]
$$


Here $V$ is the volume at pressure $P$ and temperature $T, A=\left(\delta_{T}+1\right)$. o refers to their value at room temperature and atmospheric pressure. Differentiation of Eq. (2) (i.e calculating $\partial P / \partial V)_{T}$ and multiply the result by (- $V$ ) gives (Kumar 2000; Kumar 2002):

$$
\frac{B_{T, P}}{B_{o}}=\left[1-\frac{1}{A} \ln \left\{1+\frac{A P}{B_{o}}-A \alpha_{o}\left(T-T_{o}\right)\right\}\right]\left[1+\frac{A P}{B_{o}}-A \alpha_{o}\left(T-T_{o}\right)\right]
$$

$B_{T, P}$ is bulk modulus at temperature $T$ and pressure $P$. In a particular condition $(P=0)$, Eq.(3) may be rewritten as follow:

$$
\frac{B_{T}}{B_{o}}=\left[1-\frac{1}{A} \ln \left\{1-A \alpha_{o}\left(T-T_{o}\right)\right\}\right]\left[1-A \alpha_{o}\left(T-T_{o}\right)\right]
$$

$\delta_{T}$ is temperature dependant parameter (Vinet et al.,1989) this dependence is given by the following empirical relationship (Chandra et al., 2008)

$$
\delta_{T}=\delta_{T_{O}}\left(\frac{T}{T_{o}}\right)^{k}
$$

Where: $T_{o}$ is the room temperature and $\delta_{T_{O}}$ is the value of Anderson-Gruneisen parameter at $T=T_{o} . k$ is a dimensionless thermo elastic parameter which can be calculated from the slope of the graph plotted between $\log \delta_{\mathrm{T}}$ and $\log \left(T / T_{\mathrm{o}}\right)$ (Upadhyay et al., 2011).

\section{Method 3}

The following expression is derived theoretically by Garai and Laugier (Garai and Laugier, 2007):

$$
B_{T}=B_{T=0} \operatorname{Exp}\left[-\int_{T=0}^{T} \delta_{T} \alpha_{V} d T\right]
$$

Where: $B_{T=0}$ is the bulk modulus at absolute zero temperature. In the above reference the integration was done numerically by using linear polynomials with correlation coefficient and the derived analytical solution for the temperature dependence of the isothermal bulk modulus has been applied to ten substances. They assume that the Anderson-Gruneisen parameter is approximately constant at temperatures above the Debye temperature. To do the integration in Eq. (6) we have to take into account the linear variation of $\alpha_{V}$ with $T$ which can be scripted as follows (Anderson, 1995):

$$
\alpha_{V}=\alpha_{o}\left[1+\alpha_{o} \delta_{T}\left(T-T_{o}\right)\right]
$$

Where: $T_{o}=300 \mathrm{~K}$. Substituting Eq.(7) in Eq.(6). The steps of integration are:

$$
\begin{aligned}
& B_{T}=B_{T=0} \operatorname{Exp}\left[-\delta_{T} \int_{T=0}^{T}\left[\alpha_{o}+\alpha_{o}^{2} \delta_{T}\left(T-T_{o}\right)\right] d T\right] \\
& B_{T}=B_{T=0} \operatorname{Exp}\left[-\delta_{T}\left\{\int_{T=0}^{T} \alpha_{o} d T+\int_{T=0}^{T} \alpha_{o}^{2} \delta_{T} T d T-\int_{T=0}^{T} \alpha_{o}^{2} \delta_{T} T_{o} d T\right\}\right]
\end{aligned}
$$




$$
\begin{aligned}
& B_{T}=B_{T=0} \operatorname{Exp}\left[-\delta_{T} \alpha_{o} T-\delta_{T}^{2} \alpha_{o}^{2} \cdot \frac{T^{2}}{2}+\delta_{T}^{2} \alpha_{o}^{2} T_{o} T\right] \\
& B_{T}=B_{T=0} \operatorname{Exp}\left[-\delta_{T} \alpha_{o} T\left(1+\frac{\delta_{T} \alpha_{o} T}{2}+\delta_{T} \alpha_{o} T_{o}\right)\right]
\end{aligned}
$$

To calculate the variation of bulk modulus with temperature by using Eq.(8) we need the value of $\left(B_{T=0}\right)$ which can be calculated from Eq.(1). At $T=0$ the calculated value of bulk modulus is (177 GPa) for pyrope garnet.

\section{Method 4}

Singh and Gupta proposed equation of state to determine $B_{T}$ (Chandra et al., 2008; Chandra et al., 2009). The expression for bulk modulus is given bellow :

$$
B_{T}=B_{o}\left[1-\frac{\alpha_{o} \delta_{T}}{T_{o}^{k}(k+1)}\left\{T^{k+1}-T_{o}^{k+1}\right\}\right]
$$

This equation is characterized by the presence of the dimensionless thermo elastic parameter (k) which in case that it equals 0, Eq. (9) will return to Eq. (1).

\section{Method 5}

Assuming that the product of thermal expansivity and bulk modulus will remain constant. The expression for bulk modulus as a function of temperature can be written as (Upadhyay et al., 2011):

$$
\frac{B_{T}}{B_{o}}=\frac{1+\frac{1}{A}\left[\operatorname{Exp}\left\{\alpha_{o} A\left(T-T_{o}\right)\right\}-1+\frac{\left\{\alpha_{o} A\left(T-T_{o}\right)\right\}^{3}}{6}\right]}{\operatorname{Exp}\left\{\alpha_{o} A\left(T-T_{o}\right)\right\}+\frac{\left\{\alpha_{o} A\left(T-T_{o}\right)\right\}^{2}}{2}}
$$

\section{RESULTS AND DISCUSSION}

The variation of bulk modulus with temperature for pyrope garnet is plotted in (Fig. 1) using the equations of methods (1-5) together with experimental data reported by (Anderson et al., 1992). The values of input parameters used in the theoretical equations are $\alpha_{o}=2.36 \times 10^{-5} \mathrm{~K}^{-1}$ (Anderson et al., 1992), $B_{o}=169.4 \mathrm{GPa}, \delta_{T}^{o}=6.27$ (Anderson, 1995 ) and $k=0.018$ (Upadhyay et al., 2011).

In method 1 Eq.(1) is the simplest form of the temperature dependence of bulk modulus. In addition, the Anderson- Gruniesen parameter is considered to be temperature independent. Nevertheless, (Fig.1) shows that Eq. (1) has a good agreement with experimental data.

In method 2 Eq. (4) is used to calculate the variation of $B$ with $T$ taking into account that the Anderson- Gruniesen parameter varies with $T$ according to Eq. (5). The results of this method also agree with the experimental data.

In method 3 Eq. (6) has some difficulties such as the way of integration, the correlation coefficient, considering the Anderson- Gruniesen parameter constant and needing the exact 
value of $B$ at $T=0$. The results of this method i.e. Eq. (8) shown in Fig. (1) have less agreement with the experimental data than the other methods.

In method 4 Eq. (9) needs the value of the parameter $k$ which is available for pyrope garnet. The results show a good agreement with the experimental data and the other methods.

In method 5 Eq. (10) is used and the Anderson- Gruniesen parameter is considered to be a temperature dependent parameter. The results shown in Fig. (1) have a good agreement with the experimental data.

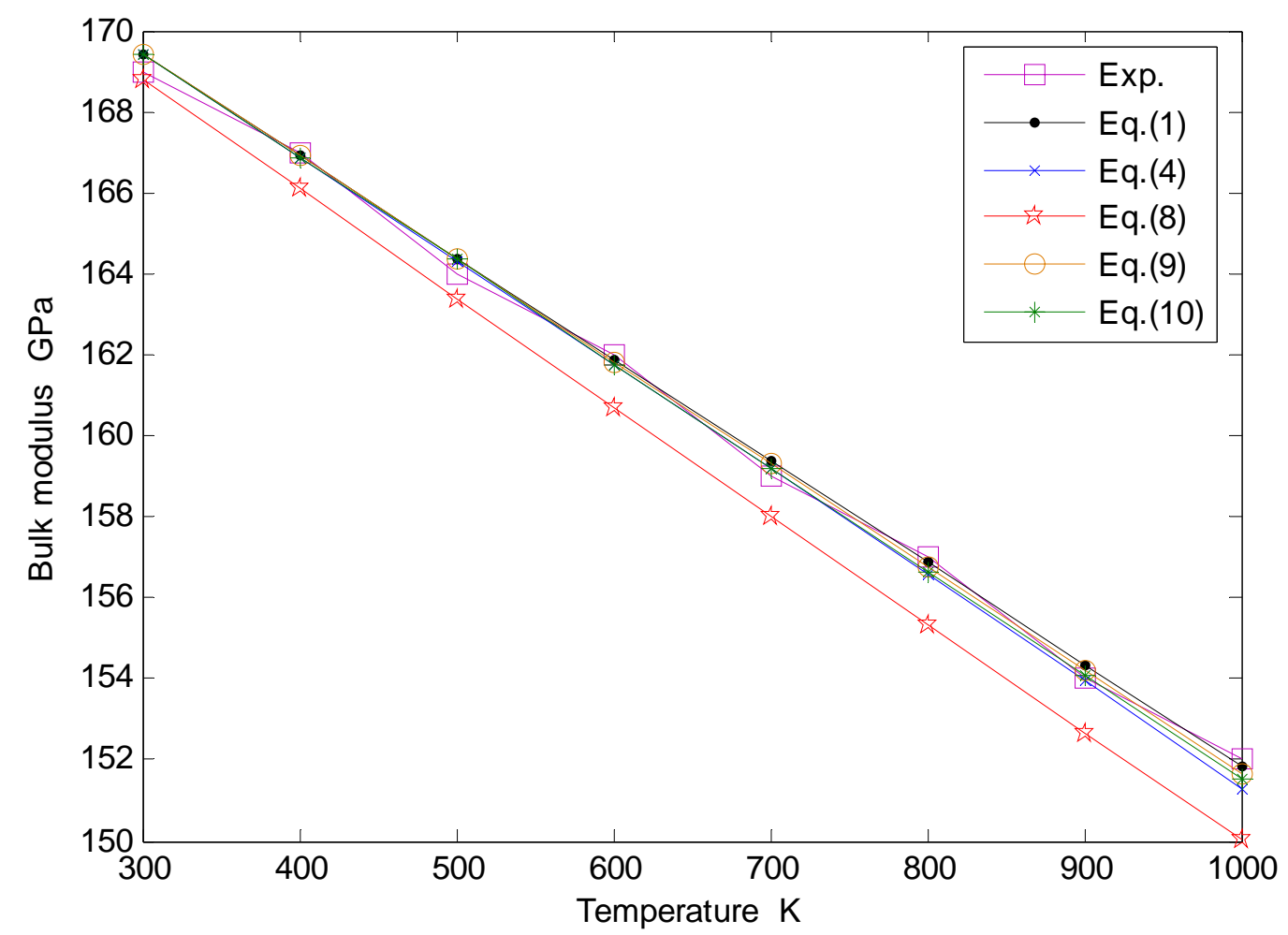

Fig. 1: The variation of bulk modulus with temperature for pyrope garnet using different theoretical methods, with experimental data from (Anderson et al., 1992).

\section{CONCLUSIONS}

The variation of bulk modulus with temperature is shown in Fig. (1) using five theoretical equations along with the experimental data for pyrope garnet. The curves of Eq. $(1,4,9,10)$ are close to each other and to experimental data especially near the room temperature and diverge a little bit at higher temperatures. The results of Eq. (8) have a less agreement with the other results. This disagreement increases at higher temperatures.

We conclude from this comparative study that the accuracy of any theoretical equation does not depend on its complications, but it depends on the way of derivation and the conditions of using the equation. 


\section{REFERENCES}

Anderson, O.L. (1995). "Equation of State for Solids for Geophysics and Ceramic Science". (Oxford: Oxford University Press) cited in Nand and Kumar, 2010.

Anderson, O. L.; Isaak, D.G.; Oda, H. (1992). High temperature elastic constant data on minerals relevant to geophysics. Rev. Geophys, 30, 57-90.

Chandra, J.; Kandpal, D.; Gupta, B.R.K. (2008). High temperature study of nanomaterials using integral form of equation of state (IFEOS). High Temperature-High Pressure, 37, 325-333.

Chandra, J.; Kandpal, D.; Gupta, B.R.K. (2009). Applicability of integral form of equation of state under high temperature. High Temperature-High Pressure, 38, 13-24.

Chen, G.L.; Cooke, J.A.; Gwanmesia, G.D. (1999). Elastic wave velocities at $\mathrm{Mg}_{3} \mathrm{Al}_{2} \mathrm{Si}_{3} \mathrm{O}_{12}$ Pyrope Garnet to 10 GPa. American Mineralogist, 84, 384-388.

Garai, J.; Laugier, A. (2007). The temperature dependence of the isothermal bulk modulus at 1 bar pressure. J. Appl. Phys., 101, 023514.

Isaak, D.G.; Anderson, O.L.; Goto, T. (1989). Measured elastic moduli of single- crystal $\mathrm{MgO}$ up to $1800 \mathrm{~K}$. Phys. Chem. Minerals, 16, 704- 713.

Kumar, M. (1996). Temperature dependence of bulk modulus and equation of state for minerals. Physica. B, 222, 229-232.

Kumar, M. (2002). Properties of solids under the effect of high temperature and pressure. Indian J. Pure Appl. Phys., 40, 202-206.

Kumar, M. (2000). Equation of state and bulk modulus under the effect of high pressurehigh temperature. Phys Chem. Mineral, 27, 650-655.

Kumar, M.; Bedi, S.S. (1996). A comparative study of Birch and Kumar equations of state under high pressure, $\mathrm{NaCl}$ as an example. Phys Stat (Solidi) (B), 196. 303-307.

Li, L.; Weidner, D.J.; Brodholt, J.; Alfe, D.; Price, G.D. (2011). Ab initio molecular dynamic simulation on the elasticity of $\mathrm{Mg}_{3} \mathrm{Al}_{2} \mathrm{Si}_{3} \mathrm{O}_{12}$ pyrope. J. Earth Sci., 22,169-175.

Murphy, C.A. (2012). "Thermoelasticity of Hexagonal Close-Packed Iron from the Phonon Density of State". California Institute of Technology, California, USA, Thesis, $19 \mathrm{p}$.

Nand, G.; Kumar, M. (2010). Analysis of temperature dependence of thermal pressure of solids. Indian J. Phys, 84(4), 459-466.

Pal, V.; Kumar, M.; Gupta, B.R.K. (1998). A simple approach for the determination of bulk modulus and equation of state under the effect of high temperature for minerals. Phys. Chem. Minerals, 25, 227-228.

Sinogeikin, S.V.; Bass, J.D. (2000). Single-crystal elasticity of pyrope and MgO to 20GPa by Brillouin scattering in the diamond cell. Phys. Earth and Planetary Interiors, 120, 43-62.

Sinogeikin, S.V.; Bass, J.D. (2002). Elasticity of pyrope and Majorite-pyrope solid solutions to high temperatures. Earth and Planetary Sci. Lett., 203, 549-555.

Upadhyay, S.; Chandra, H.; Jushi, M.; Jushi, D. (2011). Thermoelastic properties of minerals at high temperature. Pramana J. Phys, 76, 183-188.

Vinet, P.; Ferrante, J.; Smith, J.R.; Rose, J.H. (1989). Universal features of the equation of state of solids. J. Phys., 19, L467.

Zhang, J.; Herzberg, C. (1994). Melting of pyrope, $\mathrm{Mg}_{3} \mathrm{Al}_{2} \mathrm{Si}_{3} \mathrm{O}_{12}$, at 7-16 GPa. American Mineralogist, 79, 497-503. 